Originally published as:

Shen, X., Li, Y., Gao, R., Chen, X., Liu, M., Yuan, X., Kind, R., Xiong, X., Zhang, Y., Qian, Y., Li, M., Mei, X. (2020): Lateral growth of NE Tibetan Plateau restricted by the Asian lithosphere: Results from a dense seismic profile. - Gondwana Research, 87, 238-247. https://doi.org/10.1016/i.gr.2020.06.018 


\title{
Lateral growth of NE Tibetan Plateau restricted by the Asian lithosphere: Results from a dense seismic profile
}

Xuzhang Shen ${ }^{1}$, Yingkang $\mathrm{Li}^{2}$, Rui Gao ${ }^{1,3}$, Xuanhua Chen ${ }^{3}$, Mian $\mathrm{Liu}^{4}$, Xiaohui Yuan ${ }^{5}$, Rainer Kind $^{5,}{ }^{6}$, Xiaosong Xiong ${ }^{3}$, Yipeng Zhang ${ }^{1}$, Yinping Qian ${ }^{7}$, Minjuan $\mathrm{Li}^{8}$, Xiuping Mei ${ }^{8}$

1 School of Earth Science and Engineering, Sun Yat-Sen University, Guangzhou, 510275, China

2 Geological Information Centre, Ministry of Land and Resource, Yanjiao, 065201, China

3 Chinese Academy of Geological Sciences, Beijing 100037, China

4 Department of Geological Sciences, University of Missouri, Columbia, MO 65211, USA

5 Deutsches GeoForschungsZentrum GFZ, Telegrafenberg, 14473 Potsdam, Germany

6 Freie Universität, Fachrichtung Geophysik, Malteserstrasse 74-100, 12249 Berlin, Germany

7 Earthquake Administration of Guangdong Province, Guangzhou, 510070, China

8 Earthquake Administration of Guangdong Province, Lanzhou, 730000, China

\begin{abstract}
We present high-resolution receiver function images along a 700-km long dense seismic array extending from northern Tibetan Plateau to the Alxa block, crossing the entire Qilian thrust belt (QTB). The dense stations, with less than $\sim 2 \mathrm{~km}$ station intervals, allow the receiver functions to unveil unprecedented details of crustal structures across the northern frontier of the growing Tibetan Plateau. The migration image shows a thickened and strongly deformed QTB crust, with an uneven Moho and complex internal structures that are indicative of pure-shear shortening. The Alxa block, in contrast, has a thinner crust, a flat Moho, and little internal crustal deformation. These results suggest that the lateral growth of NE Tibetan Plateau is restricted by the strong Asian lithosphere, which shows no visible subduction beneath the Tibetan Plateau as previously suggested.
\end{abstract}

Key words: Northern Tibetan Plateau; Qilian thrust belt; pure-shear crustal shortening; dense seismic array; receiver function 


\section{Introduction}

It is well known that the Tibetan Plateau has risen from the Indian-Eurasian continental collision (Powell and Conaghan, 1975; Yin and Harrison, 2000), but how the plateau has grown laterally remains uncertain. Classical models, either based on continuum mechanics (England and Houseman, 1986) or physical experiments (Tapponnier et al., 1982), all predict northward growth of the plateau. But how does the plateau grow laterally, and what controls the present shape of the Tibetan Plateau, are questions without clear answers. Some studies have suggested that the Tibetan Plateau has grown laterally with sequential subduction (underthrusting) of slices of the Asian lithosphere under it (Tapponnier et al., 2001). This process would lead to simple shear deformation in northern Tibetan Plateau, with a dipping Moho and localized deformation along the shear zones (Figure 1a). Other studies, based on the lack of late Cenozoic deformation in the crust (Yuan et al., 2013) or mantle lithosphere (Shen et al., 2017) north of the plateau-bounding faults, have suggested that the Tibetan orogenesis has been largely limited between the rigid Asian lithosphere and the indenting Indian plate (Yuan et al., 2013; Shen et al., 2015). In this case, the northern margin of the Tibetan Plateau would be dominated by pure-shear crustal deformation, which could cause localized deformation of the Moho, crust buckling, and bivergent fault-propagation (Figure 1b).

The Qilian thrust belt (QTB), located near the northeastern margin of the Tibetan Plateau (Figure 2a) and is actively deforming (Li et al., 2018; Zheng et al., 2013), is an ideal place to resolve the different models of the lateral growth of the Tibetan Plateau. Many recent seismological studies, using both active and passive sources, have explored the crustal and lithospheric structures in this region, but the interpretations have been controversial. For example, some have suggested subduction of the Asian lithosphere (Ye et al., 2015), whereas others show passive and limited deformation of Asian lithosphere (Shen et al., 2015; Shen et al., 2017b). A major problem is the lack of sufficient resolution in these studies. Passive- 
source broadband seismic experiments usually have low resolution for crustal structure images because of large inter-station distance, often $>10-20 \mathrm{~km}$. Reducing the station spacing requires large number of broadband instruments and is costly to operate. A more plausible and economic way to achieve high-resolution crustal structures is to record earthquakes with highdensity short-period geophone arrays normally used by active-source seismic experiments (Yuan et al., 1997; Zhu, 2000; Liu et al., 2017 ).

In this study, we collected teleseismic waveforms recorded by a $700 \mathrm{~km}$ long seismic profile across the north Tibetan Plateau, QTB and Alxa block of Asian continent. These data enabled us to use teleseismic receiver functions to image fine crustal structures. The dense array with a station spacing less than $2 \mathrm{~km}$ ensures a higher resolution than previous passive experiments. The new data provides crustal images of dominant pure shear shortening along the NE Tibetan Plateau, which shed lights on the lateral growth of the Tibetan Plateau

\section{Data and method}

From September 28 to October 30 2016, we deployed a $700 \mathrm{~km}$ long seismic profile with 473 short-period seismometers from north Tibetan Plateau to the Alxa block, as shown in Figure 2a. This profile crosses the entire Qilian thrust system, which is the NE forefront of the growing Tibetan Plateau. This seismic array was originally designed for active source exploration. The type of the seismometer is DZS-1, made by the Chongqing Factory of Geological Instrument in China (http://www.cgif.com.cn/index.aspx). The seismometer has a flat response to velocity from $1 \mathrm{~s}$ to $60 \mathrm{~Hz}$. The sampling rate is 100 samples $\mathrm{s}^{-1}$. The average distance between two seismometers is $\sim 2 \mathrm{~km}$.

During the operational period, the seismic array recorded 21 teleseismic events with Ms larger than 5.1 within an epicentral distance range between $30^{\circ}$ and $95^{\circ}$ (Figure 2b). We use waveforms of these events to study the crustal structures using the receiver function method, 
which is commonly used to study discontinuities in the crust and upper mantle by isolating the P-to-S converted waves (Langston, 1979; Yuan et al., 1997; Kumar et al., 2006; Shen et al., 2017b). This method has been widely used to process broad-band seismic waveforms. Here we apply the receiver function method to the short period waveforms.

The earthquake parameters were taken from the global USGS (US Geological Survey) catalog (http://neic.usgs.gov/neis/epic/epic global.html). We applied a low-pass filter with $2 \mathrm{~Hz}$ to the raw waveforms to eliminate noise. The waveforms have been rotated from the north-eastvertical (N-E-Z) components to the P-SV-SH directions (L-Q-T) according to the theoretical back-azimuth and incident angle. Only the waveforms with clear P onset were selected. We cut the selected waveforms $20 \mathrm{~s}$ before and $100 \mathrm{~s}$ after the P-arrival, and then constructed the receiver functions by deconvolving the $\mathrm{L}$ component from $\mathrm{Q}$ component in time domain as described by Kumar et al. (2006). Receiver functions with obvious abnormal shape were rejected. We obtained 1751 receiver functions. For the raw receiver functions, we applied again a low-pass filter of $1 \mathrm{~Hz}$ to further suppress noise and to enhance waveform coherence. In order to pick up the P-S conversion signals from Moho and other interfaces, the moveout correction has been used to all receiver functions to correct for the variation of epicentral distance. The reference distance is set to $65^{\circ}$ with $20 \mathrm{~km}$ focal depth.

Because of the massive observations and the small station spacing, coherent P-S conversion signals from the Moho can be detected on the receiver functions from a single event (Figure 3). Assuming a Moho depth of $50 \mathrm{~km}$ and using the IASP91 model (Kennett and Engdahl, 1991), here we calculated the pierce points of PMs (P-to-S conversion from Moho) for all the receiver functions (Figure 2a). The remarkable signals in Figure 3 between 5-7.5 s represent the PMs phase from Moho, which varies in depth beneath different blocks. The Moho is deeper beneath the QTB.

Figure 4 shows the binning stacked receiver functions along the same profile from all events. 
Comparing with Figure 3, the Moho signal becomes clearer with more continuity. The dominant feature is the flat Moho beneath the Alxa block and the Qaidam basin, while the thickened crust is beneath the QTB. The Hexi corridor is a transition zone where the Moho deepens from Alxa to the Tibetan Plateau.

In order to investigate the Moho and interfaces within the crust, we used the common conversion point $(\mathrm{CCP})$ stacking method to construct migration images of receiver functions (Yuan et al., 1997). This method converts the time series receiver functions into spatial domain within one Fresnel's zone along the ray path. Here, we constructed the migration image with CCP stacking method down to a depth of $100 \mathrm{~km}$ along profile AA' shown in Figure $2 \mathrm{a}$ with a focus of the crustal structures. The model space was divided into grids of 0.5 $\mathrm{km}$ in both horizontal and vertical directions. The local velocity model from tomography (Ding et al., 2017) and crustal thickness from Crust1.0 (Laske et al., 2013) were used for the ray tracing. The influence from topography was also considered. The starting depth $(0 \mathrm{~km}$ in the migration image) of the migration is from sea level; the travel time above the sea level has been corrected according to the Crust1.0 model. Figure 5a shows the migration image along the profile tracing the ray path without smoothing. To highlight the structural features, the profile was smoothed by a Gaussian window of $5 \mathrm{~km}$ in the horizontal and $2.5 \mathrm{~km}$ in the vertical directions(Figure 5b).

\section{Results}

The most remarkable signals in migration images (Figure $5 \mathrm{a}$ and $5 \mathrm{~b}$ ) are positive converted phases near the depth of $50 \mathrm{~km}$, which we interpret as Ps converted signals from the Moho. Beneath the Alxa block north of latitude $40^{\circ} \mathrm{N}$, the Moho is continuous and flat at a depth of $45 \mathrm{~km}$. Beneath Hexi corridor between Heli Shan and the northern flank of Qilian Shan at $\sim 39^{\circ} \mathrm{N}$, the Moho depth increases sharply from $\sim 45 \mathrm{~km}$ to $\sim 65 \mathrm{~km}$. Beneath the QTB, the Moho is at an average depth of $60 \mathrm{~km}$. It is severely folded and segmented with a strong 
relief. Further south beneath the Qaidam basin, the Moho shallows to a depth of $\sim 55 \mathrm{~km}$ and is relatively flat.

In addition, a number of positive interfaces appear above the Moho at both sides of the QTB (Figure 5b). The signals from the Moho and the inclined positive interfaces can also be traced in the migration image without smoothing (Figure 5a). Although it is difficult to conclude that every inclined positive signal within the crust represents a determined interface because of the multiples interference from shallow structures, the complicated signals within the crust distinguish the QTB from the Alxa block and Qaidam basin.

The interfaces within the crust (Figure 5b) could be artificial. The dense stations along our profile allow us to test the stability and the validity of these results. We randomly selected the stations to construct the migration image. Figures 6a-f show the migration images with all, and subsets of $90 \%, 80 \%, 70 \%, 60 \%$ and $50 \%$ randomly selected data without smoothing, and Figures $7 \mathrm{a}-\mathrm{f}$ show the migration images as Figure 6 with smoothing. The crustal interfaces and the Moho signals in Figure $5 \mathrm{~b}$ are consistent features in different data selections, attesting to the stability and validity of these signals.

By the way, in order to show the original observations clearly, We added the Figures S1-S5 of the receiver function profiles and CCP stacks same as Figures 3-7 but without interpretation information in supplementary.

\section{Discussion}

Previous seismic studies of passive sources (Pan and Niu, 2011; Shen et al., 2011; Tian et al., 2013; Tian et al., 2014; Shen et al., 2017a) indicated strong variations in the crustal thickness across northeastern Tibetan Plateau. The large station intervals $(>20 \mathrm{~km})$ in these studies have limited the spatial resolution of the crustal structures. The dense stations along our profile 
permit high-resolution images that reveal clear and strong crustal deformations across the northeastern Tibetan Plateau.

The Alxa block, with a flat Moho and continuous interfaces within the crust, indicates no significant internal deformation. Under the Qaidam Basin, the Moho is relatively shallow and flat,consistent with it being a relatively strong block (Wittlinger et al., 1996). But the Moho signals beneath the south QTB are very complicated with obvious offset and superposition around latitude equal to $\sim 37$ degree, which appear on almost all the randomized profiles of Figure 6. The thickened crust of Alxa beneath the boundary region of the northern Tibetan plateau has been observed by a very closely located wide-angle reflection profile (Zeng et al., 1998; Gao et al., 1999). The flat Moho at $~ 55 \mathrm{~km}$ depth beneath Qaidam basin in our results is consistent with another wide-angle reflection profile located $30 \mathrm{~km}$ east of our profile (Jiang et al., 2006), although our image is clearer. The crustal structure of the QTB, marked by the complex crust buckles and the deep, discontinuous and uneven Moho, is indicative of pureshear crustal shortening between a rigid Alxa lithosphere and a relatively strong Qaidam block.

The complex crust buckles indicated the possible interfaces above Moho, which multiples might interfere with the P-to-S converted phases from deeper arrivals such as the Moho. In order to test the influences of multiples from shallower interfaces, we constructed the models including one-layer sediment with different thickness from $1 \mathrm{~km}$ to $20 \mathrm{~km}$ (Figure 8), and calculated the synthetic receiver functions using the reflectivity method and Computer Programs in Seismology (http://www.eas.slu.edu /eqc/eqccps.html). According to the synthetic receiver functions with different sediment thickness, the multiples from the interfaces with 10-16 km depth have some influences on the P-to-S conversion from $60 \mathrm{~km}$ depth Moho beneath South QTB. The migration image of Figure 5 indicated that the most positive signals representing the interfaces within the crust are out of the depth range with 10-16 km depth, which has small influence on PMs phase. In addition, we found the multiple 
from Moho is not so clear on the receiver functions, which imply that the multiples might be suppressed in our observations because of instruments or observational environments. So the crust buckles are reliable.

The continuous positive-to-negative signals near the surface throughout the profile are a combination of data processing artifact (imperfect component rotation) and converted phases at near-surface interfaces, e.g., base of the sedimentary layer. A down warping of a positive phase to a maximum depth of $\sim 5 \mathrm{~km}$ can be clearly seen beneath the Hexi corridor. This feature is stable in the migration images with different random station selections (Figures 6 and 7). It is well separated from the surface and therefore should indicate a real physical interface. We interpret this interface as the crystalline basement of the Hexi corridor. The Hexi corridor is the foreland basin of the north Tibetan Plateau, a direct response to the growth of the plateau (Lease et al., 2012; Métivier et al., 1998; Meyer et al., 1998).

Previous results from S receiver functions (Shen et al., 2015; Xu et al., 2019) and surface wave tomography (Wei et al., 2017) suggested limited southward underthrusting of the Asian lithosphere beneath the northeastern margin of the Tibetan Plateau, and no large-scale subduction of Asian lithosphere beneath the QTB. Inversion of receiver functions of a dense broadband seismic array in NE Tibetan Plateau indicates that crustal deformation beneath northeastern Tibetan Plateau is partially accommodated by the thickening of the upper-middle crust (Wang et al., 2017) marked by the low velocity zones. Diverse receiver function studies (Pan and Niu, 2011; Shen et al., 2011; Tian et al., 2013; Tian et al., 2014; Wang et al., 2017) also indicate relative small $\mathrm{Vp} / \mathrm{Vs}$ velocity ratio beneath the $\mathrm{QTB}$, suggesting that deformation in NE Tibetan Plateau is dominated by upper-crustal thickening (Tian et al., 2013). These results are consistent with our interpretation that the dominant deformation of the QTB is pure-shear crustal shortening.

Seismicity and focal depths offer additional information about whether or not the Asian 
lithosphere is subducting under the Tibetan Plateau. Figure 9a shows the distribution of earthquakes (ML >3.0) in the study area with the depth marked by color (Feng et al., 2012). All the earthquakes occurred within the crust, and most of them are shallower than $20 \mathrm{~km}$. In other words, there is no evidence of deeper earthquakes usually associated with subduction zones. To see the relationship between seismicity and the crustal structures, in Figure $9 \mathrm{~b}$ we compare earthquakes within a swath of $100 \mathrm{~km}$ wide along profile AA' (Figure 2a) with the Moho and crustal interfaces from the receiver functions (Figure 5b). In the southern edge of the Alxa block, some shallow earthquakes may be related with thin-skinned thrusting of the sedimentary cover. Earthquakes are more abundant and deeper under the QTB, consistent with crustal shortening and thickening here.

As illustrated in Figure 1, the shape of the Moho and other interfaces within the crust near the margins of the Tibetan Plateau are indicative of the model of its growth. The crust buckles represented by the bivergent interfaces toward the QTB and deformed Moho beneath the QTB is consistent with pure-shear crust shortening, resulting from compression between the relatively strong and rigid Alxa and Qaidam blocks. Figure 10 is a cartoon summarizing our observations and interpretation for the mode of the lateral growth of northern Tibetan Plateau. During the Indo-Eurasian collision, the Alxa block has remained undeformed, restricting the northward growth of the Tibetan Plateau. The strongly deformed QTB was caused by pureshear crustal shortening between the rigid Alxa block and the relatively stronger Qaidam Basin. The slight bending near the southern edge of Alxa block with the bended sediment base beneath the Hexi corridor is a passive and limited response to the growth of northern Tibetan Plateau. Our results do not indicate underthrusting of the Asian lithosphere under the Tibetan Plateau. Similar to the undeformed crust in the Alxa, the mantle lithosphere under Alxa is also largely intact (Shen et al., 2015).

Although the main effect on the crust thickening beneath QTB is from the lateral extension of Tibetan Plateau after Indo-Eurasian collision, the more ancient tectonic processing also left 
the signs in the deep structures. The results from petrology (Song et al., 2014) indicated that the Qaidam basin and QTB experienced a complete history from prior seafloor subduction to continental collision from the Neoproterozoic to the Paleozoic. So the ancient crust boundary between Qaidam and QTB has been exist far earlier before the Indian-Eurasia collision. The offset and superposition of Moho beneath the boundary between Qaidam basin and QTB might be the traces of the tectonic evolution with different geologic period.

\section{Conclusions}

High density seismic array revealed fine crustal structures along a profile crossing the boundary region between northern Tibetan Plateau and the Alxa block of the Asian plate. The results indicate a contrasting crustal thickness from $\sim 65 \mathrm{~km}$ beneath northern Tibetan Plateau to $\sim 45 \mathrm{~km}$ beneath the Alxa block. The entire crust beneath the Qilian Thrust Belt has been homogeneously thickened by pure-shear shortening.

The Alax block is undeformed with a flat Moho, implying that the rigid Asian lithosphere has restricted the northward growth of the Tibetan Plateau. The strongly deformed QTB has resulted from convergence between the rigid Alax block and the relatively strong Qaidam Basin. The process is ongoing with the crust buckles, producing localized and active seismicity.

Acknowledgements: $X$. Shen acknowledges the Second Tibetan Plateau Scientific Expedition and Research Program (STEP) (2019QZKK0701), the National key Research and Development Program of China (2017YFC1500100), National Natural Science Foundation of China (Grant 41874052 and 41730212). Guangdong Province Introduced Innovative R\&D Team of Deep earth exploration and resource environment (2017ZT07Z066). Y. Li, X. Xiong, R. Gao acknowledge China Geological Survey project (Grants.DD201600832 and DD20179342). X. Mei acknowledgesNational Natural Science Foundation of China 
(Grant 41704057). Some figures were plotted with Generic Mapping Tools (Wessel and Smith, 1995), and computations were done in Seismic Handler (K. Stammler).

\section{References}

Ding, Z., Cheng, B., Dong, Y., Zhao, D., 2017. Seismic imaging of the crust and uppermost mantle beneath the Qilian Orogenic Belt and its geodynamic implications. Tectonophysics 705, 63-79.

England, P. C., Houseman, G. A., 1986. Finite strain calculations of continental deformation 2. Comparison with the India-Asia collision. Journal of Geophysical Research 9, 3664-3676. Feng, J., Jiang, C., Hang, L., Hong, D., 2012. Collection and reestablish work for the earthquake observation reports of the Gansu seismographic network since 1970 and earthquake relocation. Northwestern Seismological Journal 34(8), 289-293.

Gao, R., Cheng, X. Z., Wu, G.J., 1999. Lithospheric structure and geodynamic model of the Golmud-Ejin transect in northern Tibet: Special Papers - Geological Society of America 328, 9-17, https://doi.org/10.1130/0-8137-2328-0.9.

Jiang, M., Galvé, A., Hirn, A., de Voogd, B., Laigle, M., Su, H.P., Diaz, J., Lépine, J.C., Wang, Y.X., 2006. Crustal thickening and variations in architecture from the Qaidam basin to the Qang Tang (North-Central Tibetan Plateau) from wide-angle reflection seismology. Tectonophysics 412, 121-140. http://dx.doi.org/10.1016/j. tecto. 2005.09.011.

Kennett, B. L. N., Engdahl, R., 1991. Travel times for global earthquake location and phase identification: Geophysical Journal International 105, 429-465. https://doi.or g / 10.1111/j.1365-246X.1991.tb06724.X.

Kumar, P., Yuan, X., Kind, R., and Ni, J., 2006. Imaging the colliding Indian and Asian lithospheric plates beneath Tibet. Journal of Geophysical Research 111, B06308. https://doi.org/10.1029/2005 JB003930.

Langston, C. A., 1979. Structure under Mount Rainier, Washington, inferred from teleseismic body waves. Journal of Geophysical Research 84, B4,4749-4762. 
https://doi.org/10.1029/JB084i B09p04749.

Laske, G., Masters., G., Ma, Z., Pasyanos, M., 2013. Update on CRUST1.0 - A 1-degree Global Model of Earth's Crust, Geophys. Res. Abstracts, 15, Abstract EGU2013-2658.

Lease, R. O., Burbank, D. W., Zhang, H., Liu, J., and Yuan, D., 2012. Cenozoic shortening budget for the northeastern edge of the Tibetan Plateau: Is lower crustal flow necessary? Tectonics 31, TC3011. https://doi.org/10.1029/2011TC003066.

Li, Y., Liu, M., Wang, Q., Cui D., 2018. Present-day crustal deformation and strain transfer in northeastern Tibetan Plateau. Earth and Planetary Science Letters 487, 179-189.

Liu, Z., Tian, X., Gao, R., Wang, G., Wu, Z., Zhou, B., Tan, P., Nie, S., Yu, G., Zhu, G., Xu, X., 2017, New images of the crustal structure beneath eastern Tibet from a high-density seismic array. Earth and Planetary Science Letters 480, 33-41, https://doi.org/10.1016/j.eps1.2017.09.048.

Meissner, R., Strehlau, J., 1982. Limits of stresses in continental crusts and their relation to the depth-frequency distribution of shallow earthquakes. Tectonics 1(1), 73-89.

Meyer, B., Tapponnier, P., Bourjot, L., Métivier, F., Gaudemer, Y., Peltzer, G., Shunmin, G., Zhitai, C., 1998. Crustal thickening in Gansu-Qinghai, lithospheric mantle subduction, and oblique strike-slip controlled growth of the Tibet plateau. Geophysical Journal International 135(1), 1-47. https://doi.org/10.1046/j.1365-246X.1998.00567.x.

Métivier, F., Gaudemer, Y., Tapponnier, P., Meyer, B., 1998. Northeastward growth of the Tibet plateau deduced from balanced reconstruction of the two areas: The Qaidam and Hexi corridor basins, China. Tectonics 17(6), 823-842. https://doi.org/10.1029/98TC02764.

Pan, S., Niu, F., 2011. Large contrasts in crustal structure and composition between the Ordos plateau and the NE Tibetan plateau from receiver function analysis. Earth and Planetary Science Letters 303(3-4), 291-298. https://doi.org /10.1016/j.eps1.2011.01.007.

Powell, C., Conaghan, P., 1975. Tectonic models of the Tibetan plateau. Geology (Boulder) 3(12), 727-731.

Shen, X., Kim, Y., Gan, W., 2017a. Lithospheric velocity structure of the northeast margin of the Tibetan Plateau: Relevance to continental geodynamics and seismicity. Tectonophysics 
712, 482-493. https://doi.org/10.1016/j.tecto.2017. 06.022.

Shen, X., Liu, M., Gao, Y., Wang, W., Shi, Y., An, Zhang, M., Y., Liu, X., 2017b, Lithospheric structure across the northeastern margin of the Tibetan Plateau: Implications for the plateau's lateral growth. Earth and Planetary Science Letters 459, 80-82. http:dx.doi.org/ 10.1016/j.eps1.2016.11.027.

Shen, X., Mei. X., Zhang, Y., 2011. The crustal and upper mantle structures beneath the northeastern margin of Tibet. Bulletin of the Seismological Society of America 101(6), 27822795. https://doi.org/10.1785/0120100112.

Shen, X., Yuan, X., Liu, M., 2015. Is the Asian lithosphere underthrusting beneath northeastern Tibetan Plateau? Insights from seismic receiver functions. Earth and Planetary Science Letters 428, 172-180. https://doi.org/10.1016/j.eps1.2015.07.041.

Shen, X., Liu, M., Gao, Y., Wang, W., Shi, Y., An, M., Zhang, Y., Liu, X., 2017. Lithospheric structure across the northeastern margin of the Tibetan Plateau: Implications for the plateau's lateral growth. Earth and Planetary Science Letters 459, 80-92.

Song, S. , Niu, Y., Su, L. , Zhang, C. , \& Zhang, L. . (2014). Continental orogenesis from ocean subduction, continent collision/subduction, to orogen collapse, and orogen recycling: the example of the north qaidam uhpm belt, nw china. Earth Science Reviews, 129, 59-84.

Tapponnier, P., Peltzer, G., Le Dain, A. Y., Armijo, R., Cobbold, P., 1982. Propagating extrusion tectonics in Asia; new insights from simple experiments with plasticine. Geology (Boulder) 10(12),

611-616. https://doi.org/10.1130/0091-

\section{3(1982)10<611:PETIAN>2.0.CO:2.}

Tapponnier, P., Xu, Z., Roger, F., Meyer, B., Amaud, N., Wittlinger, G., Yang, J., 2001. Oblique stepwise rise and growth of the Tibet plateau. Science 294(5547), 1671-1677. https://doi.org/10.1126/science.105978.

Tian, X., Zhang, Z., 2013. Bulk crustal properties in NE Tibet and their implications for deformation model. Gondwana Research 24(2), 548-559. https://doi.org/10. 1016/j.gr.2012.12.024.

Tian, X., Liu, Z., Si, S., Zhang, Z., 2014. The crustal thickness of NE Tibet and its implication 
for crustal shortening. Tectonophysics 634, 198-207, https://doi.org / 10.1016/j.tecto.2014.07.001.

Wang, C., Dai, J., Zhao, X., Li, Y., Graham, S. A., He, D., Ran, B., Meng, J., 2014. Outwardgrowth of the Tibetan Plateau during the Cenozoic: A review. Tectonophysics 621, 1-43. https://doi.org/10.1016/j.tecto.2014.01.036.

Wang, W., Wu, J., Fang, L., Lai, G., Cai, Y., 2017. Sedimentary and crustal thicknesses and Poisson's ratios for the NE Tibetan Plateau and its adjacent regions based on dense seismic arrays. Earth and Planetary Science Letters 462, 76-85.

Wang, X., Li, Y., Ding, Z., Zhu, L., Wang, C., Bao, X., Wu, Y., 2017. Three-dimensional lithospheric S wave velocity model of the NE Tibetan Plateau and western North China Craton. Journal of Geophysical Research 122(8), 6703-6720.

Wei, X., Jiang, M., Liang, X., Chen, L., Ai, Y., 2017. Limited southward underthrusting of the Asian lithosphere and material extrusion beneath the northeastern margin of Tibet, inferred from teleseismic Rayleigh wave tomography. Journal of Geophysical Research 122(9),71727189.

Wessel, P., Smith, W. H., 1995. New version of the generic mapping tools: Eos, Transactions. American Geophysical Union, 76, 326-329. https://doi.org/10.1029 /95EO00198.

Wittlinger, G., Masson, F., Poupinet, G., Tapponnier, P., Mei, J., Herquel, G., Guilbert, J., Achauer, U., Guanqi, X., Danian, S., 1996. Seismic tomography of northern Tibet and Kunlun: Evidence for crustal blocks and mantle velocity contrasts. Earth and Planetary Science Letters 139(1-2), 263-279. https://doi.org/10.1016/0012-821X(95)00235-5.

Xu, Q., Pei, S., Yuan, X., Zhao, J., Liu, H., Tu, H., Chen, S., 2019. Seismic evidence for lateral asthenospheric flow beneath the northeastern Tibetan Plateau derived from S receiver functions. Geochemistry, Geophysics, Geosystems 20(2), 883-894.

Ye, Z., Gao, R., Li, Q., Zhang, H., Shen, X., Liu, X., Gong, C., 2015. Seismic evidence for the North China plate underthrusting beneath northeastern Tibet and its implications for plateau growth: Earth and Planetary Science Letters 426, 109-117. https://doi.org/10.1016/j.eps1.2015.06.024. 
Yin, A., Harrison, M., 2000. Geological Evolution of the Himalayan-Tibetan orogen. Annual Review of Earth and Planetary Sciences 28, 211-280, https://doi.org/10.1146/annurev.earth.28.1.211.

Yuan, D., Ge, W., Chen, Z., Li, C., Wang, Z., Zhang, H., Zhang, P., Zheng, D., Zheng, W., Craddock, W., Dayem, K., Duvall, A., Hough, B., Lease, R., Champagnac, J., Burbank, D., Clark, M., Farley, K., Garzione, C., Kirby, E., Molnar, P., Roe, G., 2013. The growth of northeastern Tibet and its relevance to large-scale continental geodynamics: A review of recent studies. Tectonics 2013TC003348.

Yuan, X., Ni, J., Kind, R., Mechie, J., Sandvol, E., 1997. Lithospheric and upper mantle structure of southern Tibet from a seismological passive source experiment. Journal of Geophysical Research 102, B12, 27491-27500.

Zeng, R. S., Ding, Z. F., Wu, Q. J., 1998. The crustal structures from Himalaya to Qilian and its implications for continent-continent collision process. Acta Geophysica Sinica, 41, 48-60. Zheng, W., Zhang, P., He, W., Yuan, D., Shao, Y., Zheng, D., Ge, W., and Min, W., 2013. Transformation of displacement between strike-slip and crustal shortening in the northern margin of the Tibetan Plateau: Evidence from decadal GPS measurements and late Quaternary slip rates on faults. Tectonophysics 584, 267-280.

Zhu, L., 2000. Crustal structure across the San Andreas Fault, southern California from teleseismic converted waves. Earth and Planetary Science Letters 179(1), 183-190. https://doi.org/10.1016/S0012-821X(00)00101-1. 


\section{Figures}
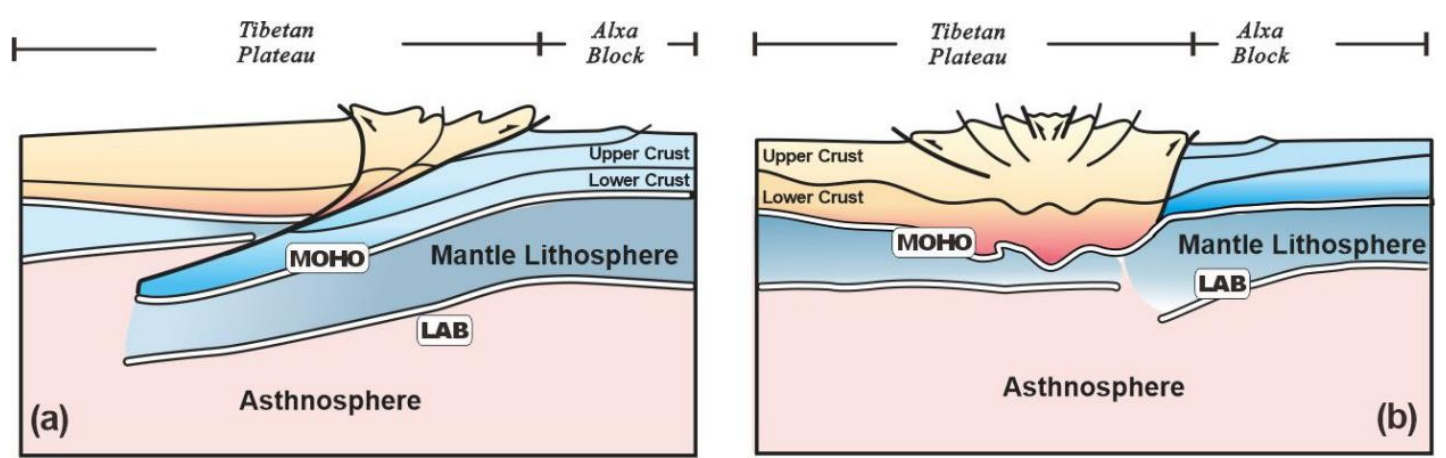

Figure 1. Conceptual model of crust deformation predicted by two hypothesized thickening models. (a) simple shear thickening, and (b) pure shear thickening 
(a)

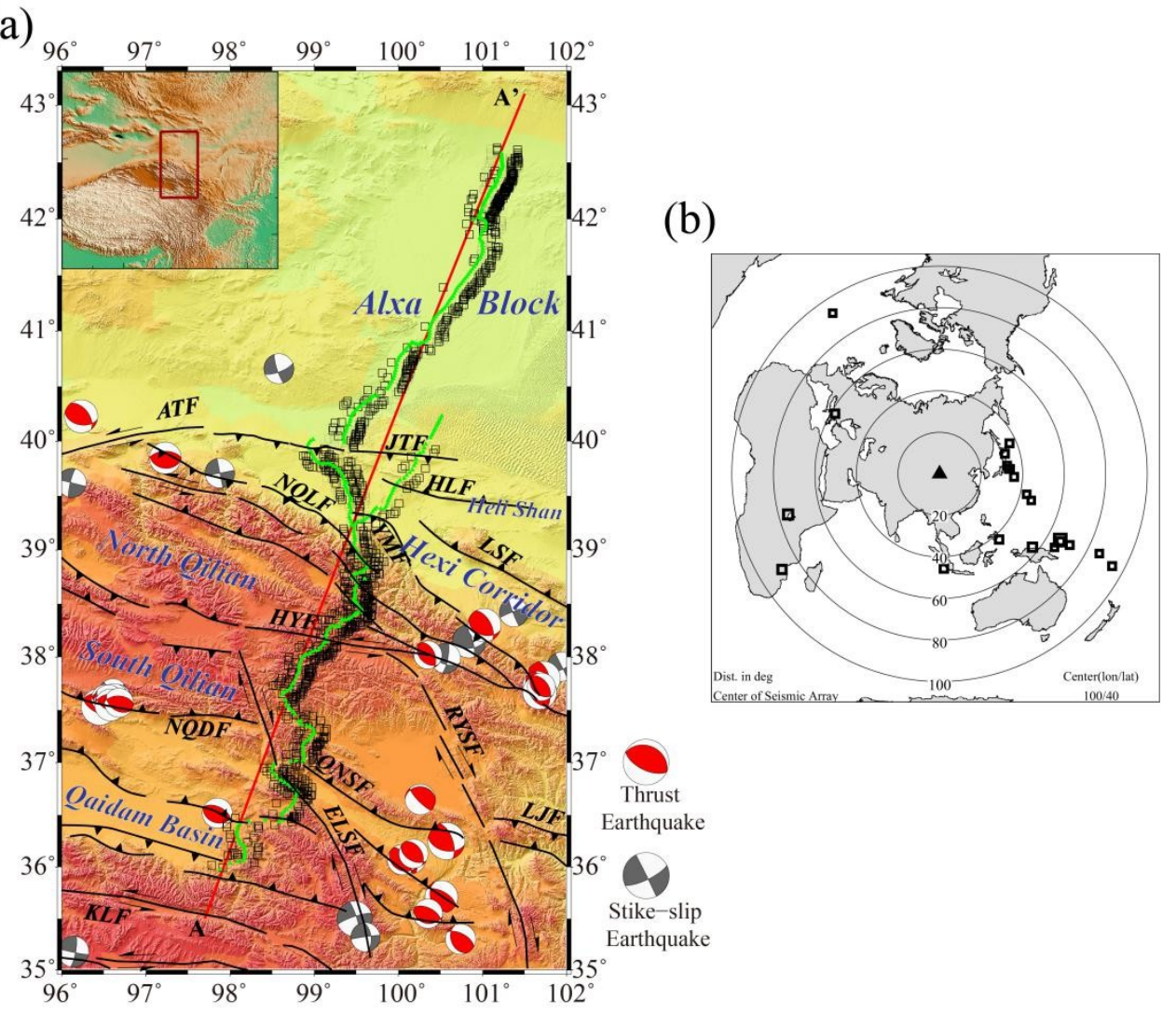

Figure 2. (a) Distribution of seismic stations on topographic relief map. Green triangles denote seismic stations. Dark yellow squares mark locations of P-to-S pierce points at $50 \mathrm{~km}$ depth. Red line labeled AA' marks the profile of receiver function image shown in Figure 3. Beachballs represent source mechanism of earthquakes since 1976 (http://www.globalcmt.org/CMTsearch.html). Black lines indicate main faults With abbreviations of ATF: Altyn Tagh fault; NQDF: North Qaidam Fault; JTF: Jinta fault; HLF: Helishan fault; LSF: Longshoushan fault; HYF: Haiyuan fault; RYSF: Riyueshan Fault; NQLF: North Qilianshan fault; YMF: Yumenshan fault; QNSF: Qinghai Nanshan fault; ELSF: Elashan fault; LJF: Lajishan fault; KLF: Kunlun fault. Inset map outlines the study area. (b) Map of teleseismic events used in this study. The triangle is the centroid location of the seismic array $\left(40^{\circ} \mathrm{N}, 100^{\circ} \mathrm{E}\right)$. Squares are event epicenters. 


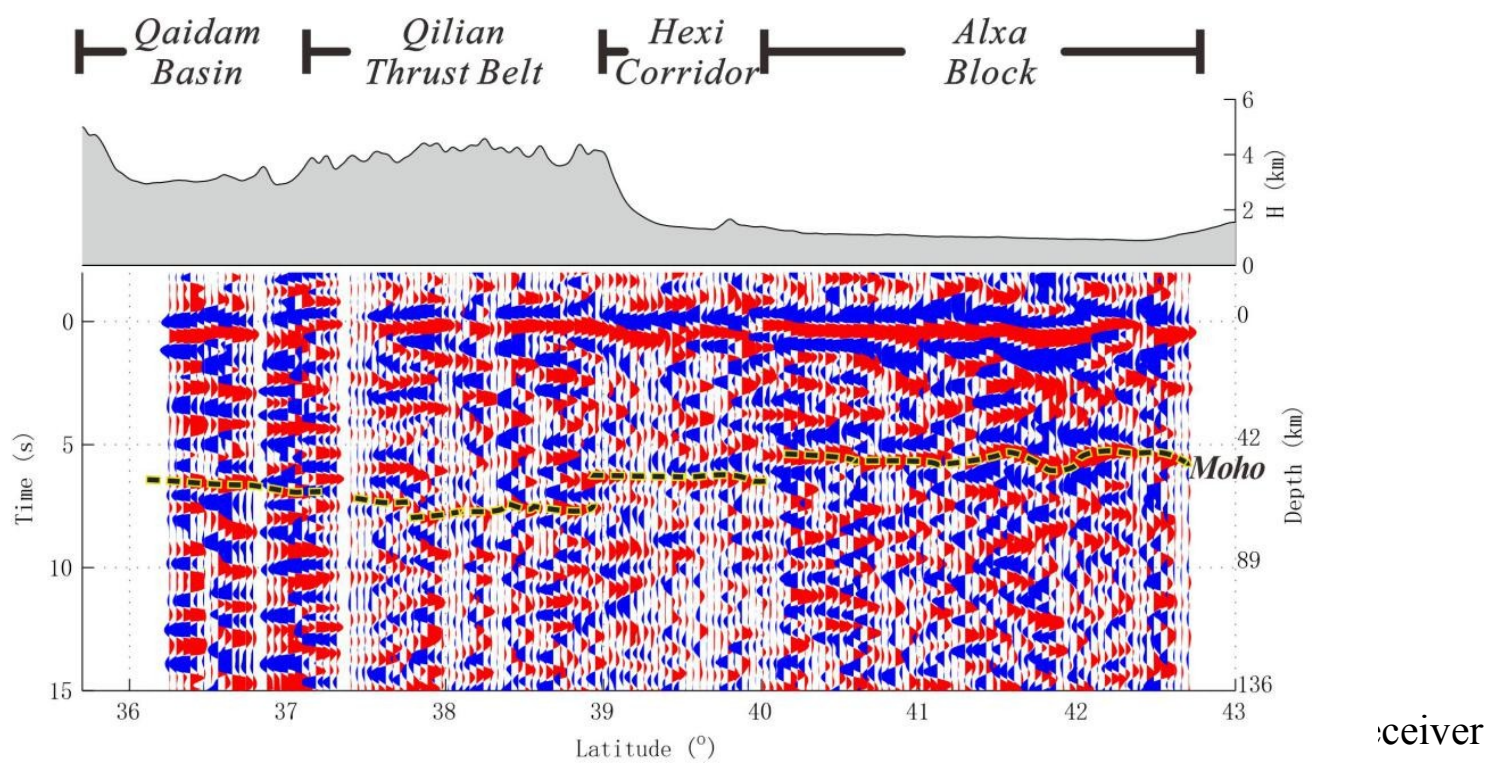

functions with PMs (Moho depth is set to $50 \mathrm{~km}$ ) pierce points in the $5 \mathrm{~km}$ horizontal intervals have been stacked. The moveout correction has been used to all receiver functions to correct the influence from distance. 


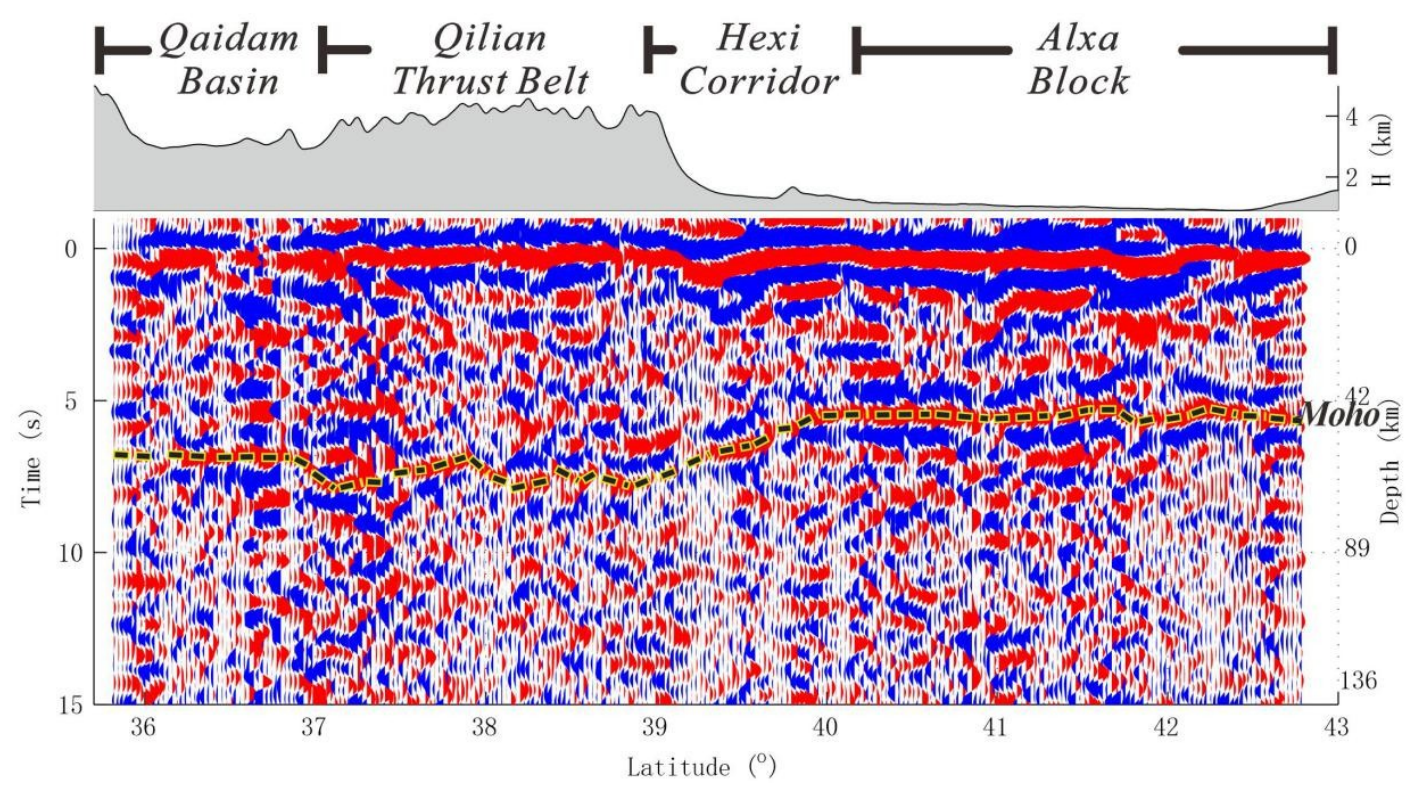

Figure 4. The stacking profile of receiver functions along the latitude. Receiver functions with PMs (Moho depth is set to $50 \mathrm{~km}$ ) pierce points in the $5 \mathrm{~km}$ horizontal intervals have been stacked. The moveout correction has been used to all receiver functions to correct the influence from distance. 

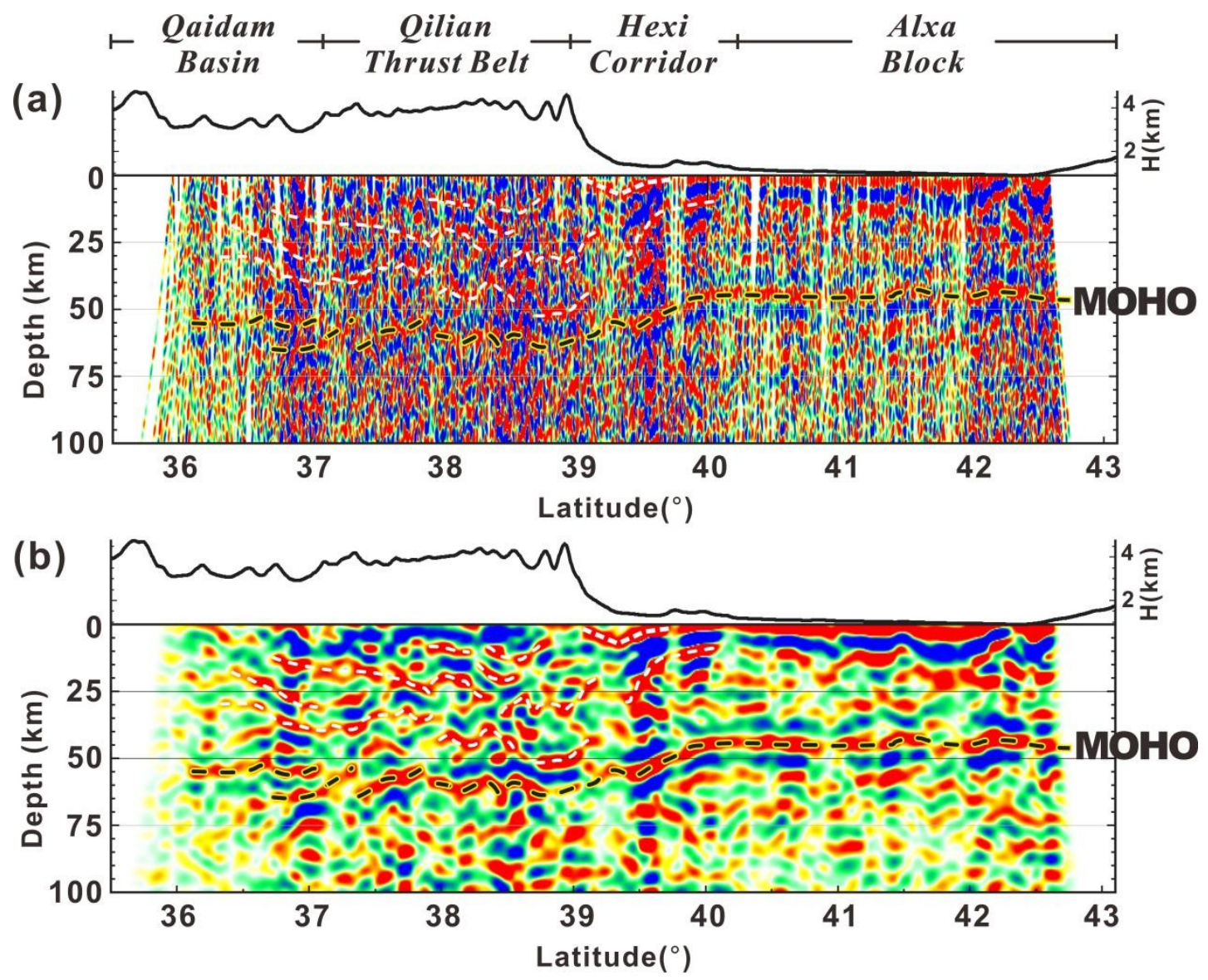

Figure 5. (a) CCP migration images of receiver functions without smoothing along the profile shown in Figure 1 with topography and main tectonic units indicated in the top panel. Red and blue colors denote positive and negative amplitudes of stacked receiver functions, respectively. Dashed lines mark interfaces, identified and discussed in this study. Moho is marked with black dashed line. The inclined upper crustal interfaces are marked by white dashed lines. (b) CCP migration images of receiver functions with smoothing. 

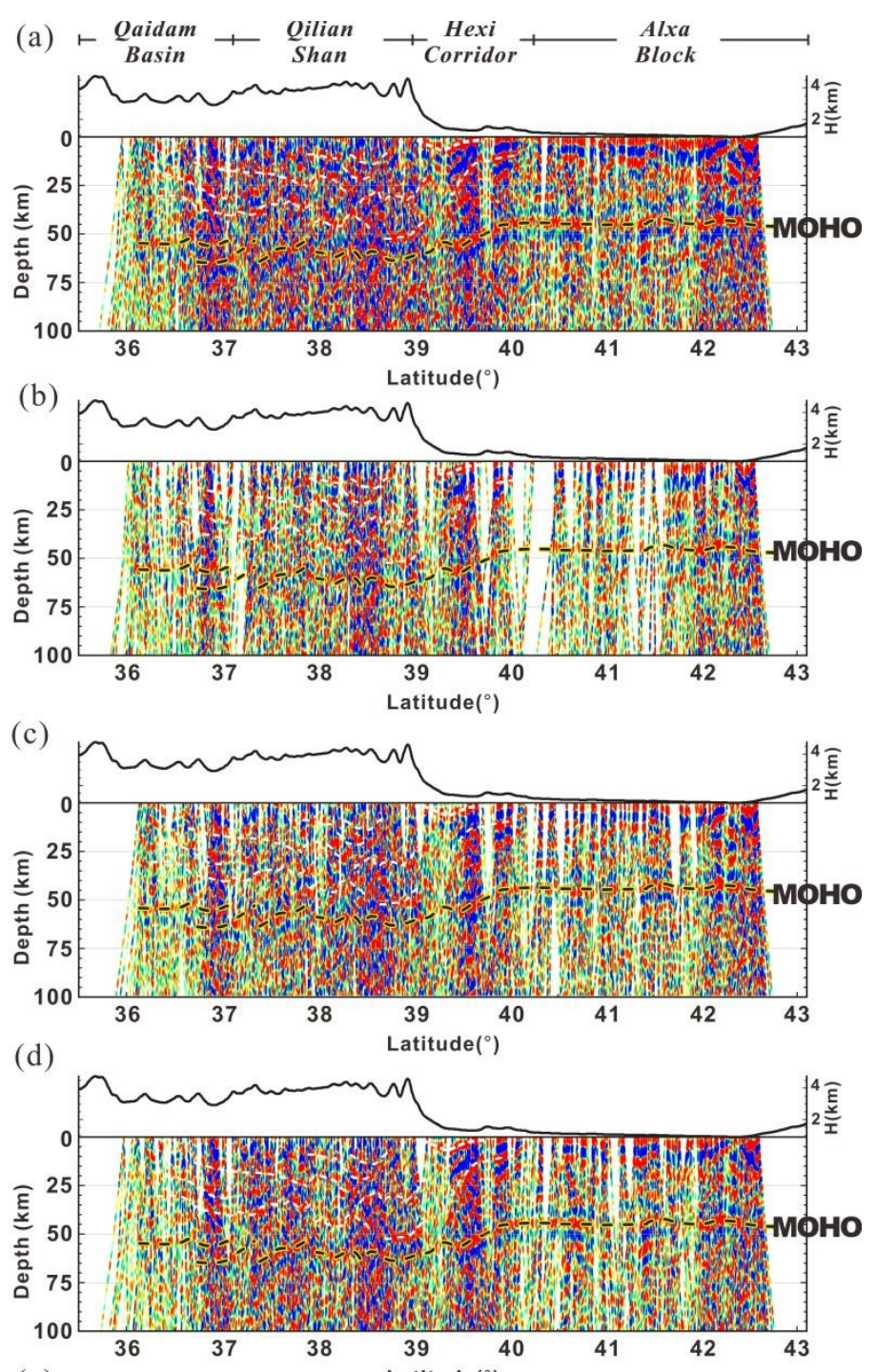

(e)
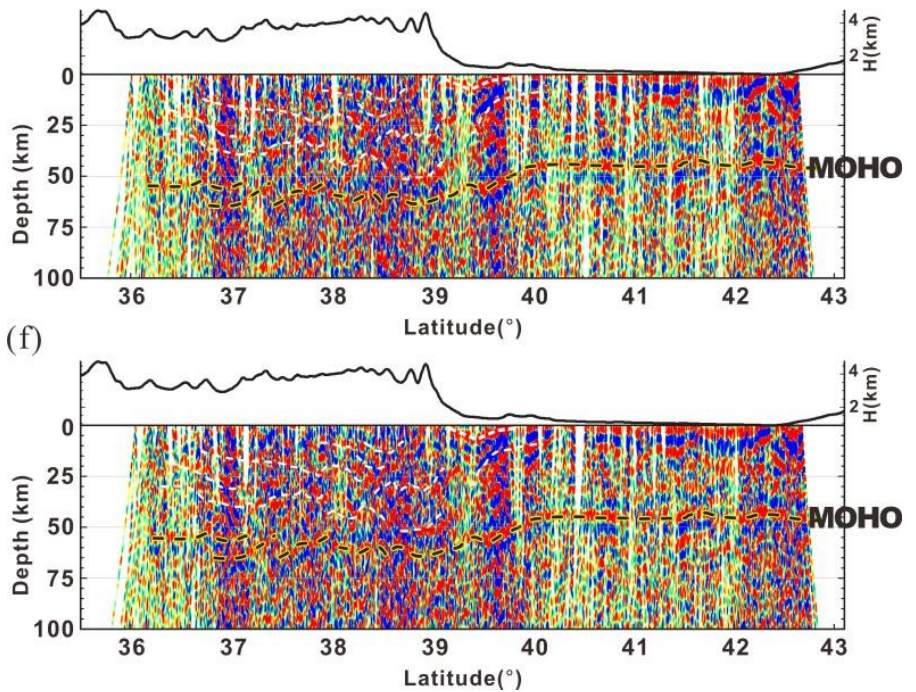
Figure 6. CCP migration images of receiver functions from random selection without smoothing. (a)-(f) represent the migration images with all, 50\%, 60\%, 70\%, 80\% and 90\% random selection without smoothing. 

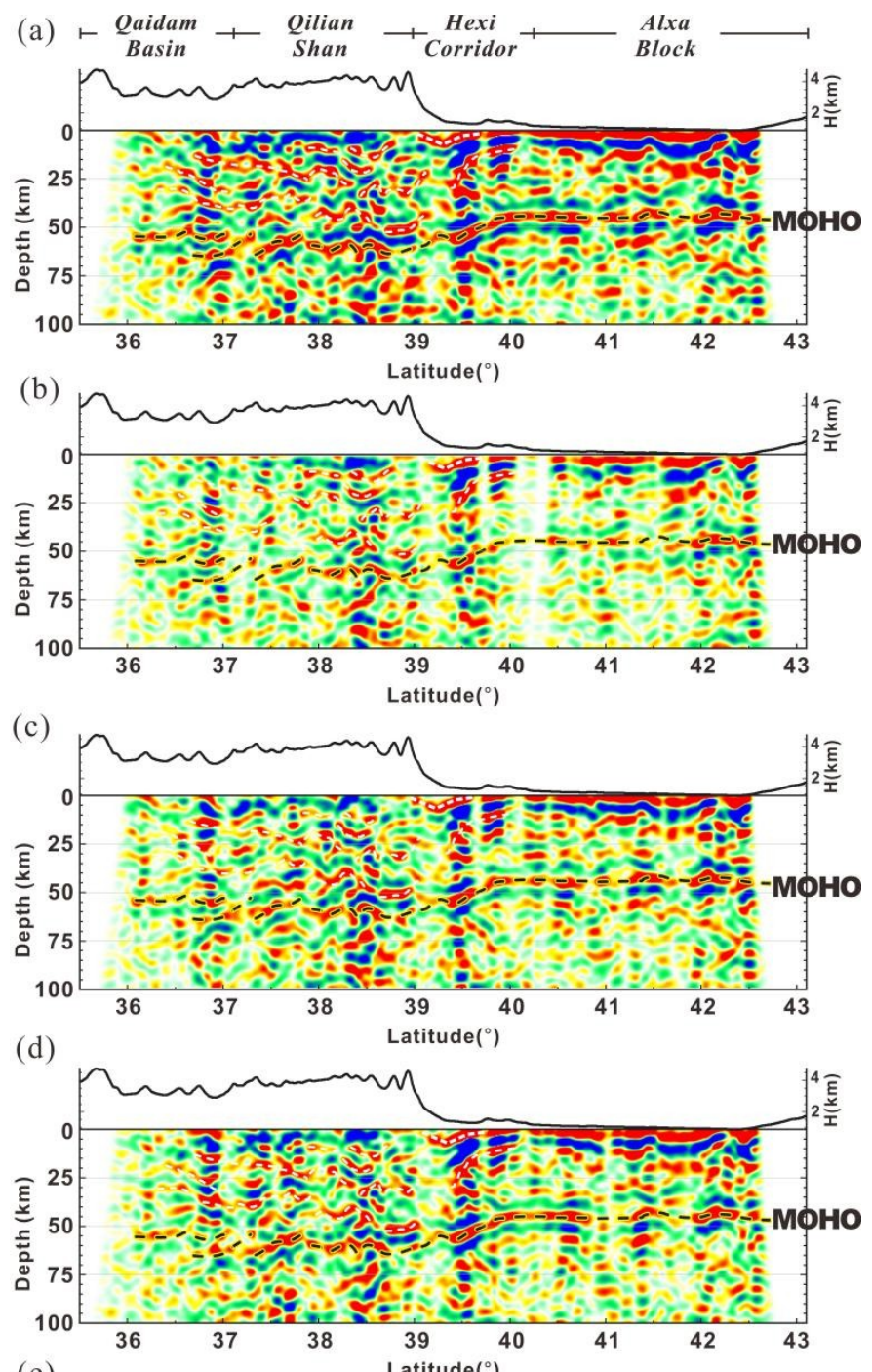

(e)

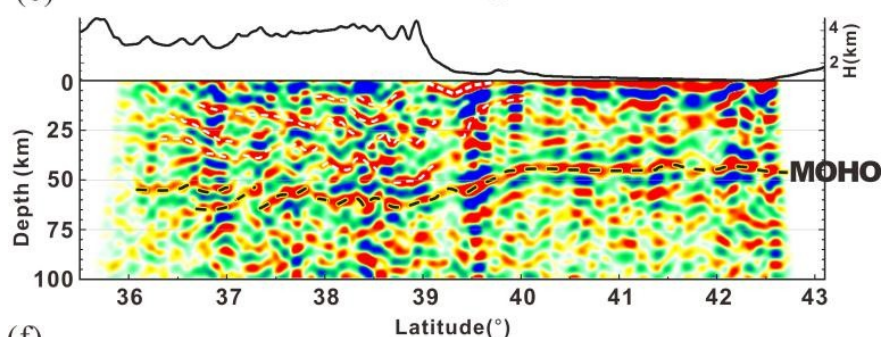

(f)

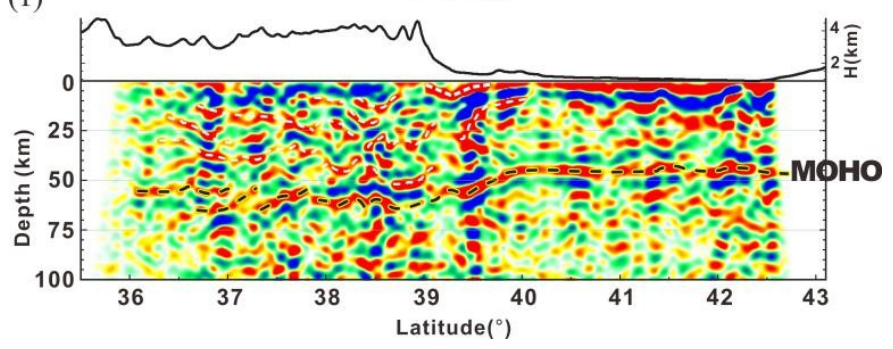


Figure 7. CCP migration images of receiver functions from random selection with smoothing. (a)-(f) represent the migration images with all, 50\%, 60\%, 70\%, 80\% and 90\% random selection without smoothing. 
(a)

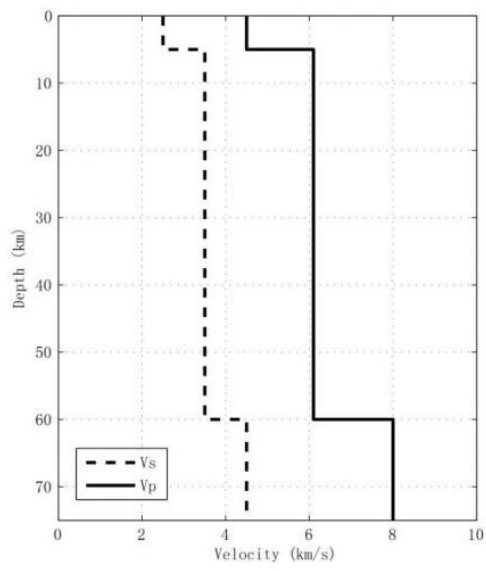

(b)

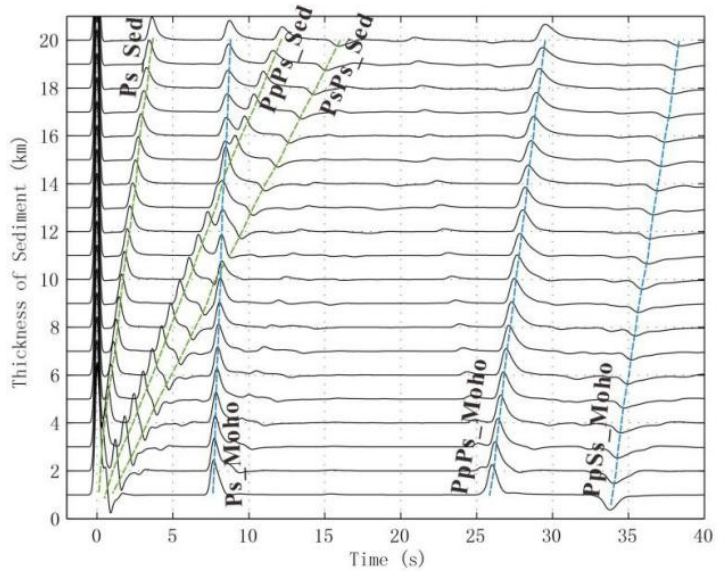

Figure 8. Model and synthetic receiver functions. (a) The model with $5 \mathrm{~km}$ thickness sediment layer, other models are similar with this except the thickness of the top layer. (b) Synthetic receiver functions from the models including one sediment layer with different thickness from $1 \mathrm{~km}$ to $20 \mathrm{~km}$ with $1 \mathrm{~km}$ step. The P-to-S converted phases and multiples from bottom of sediment and Moho are both marked. 

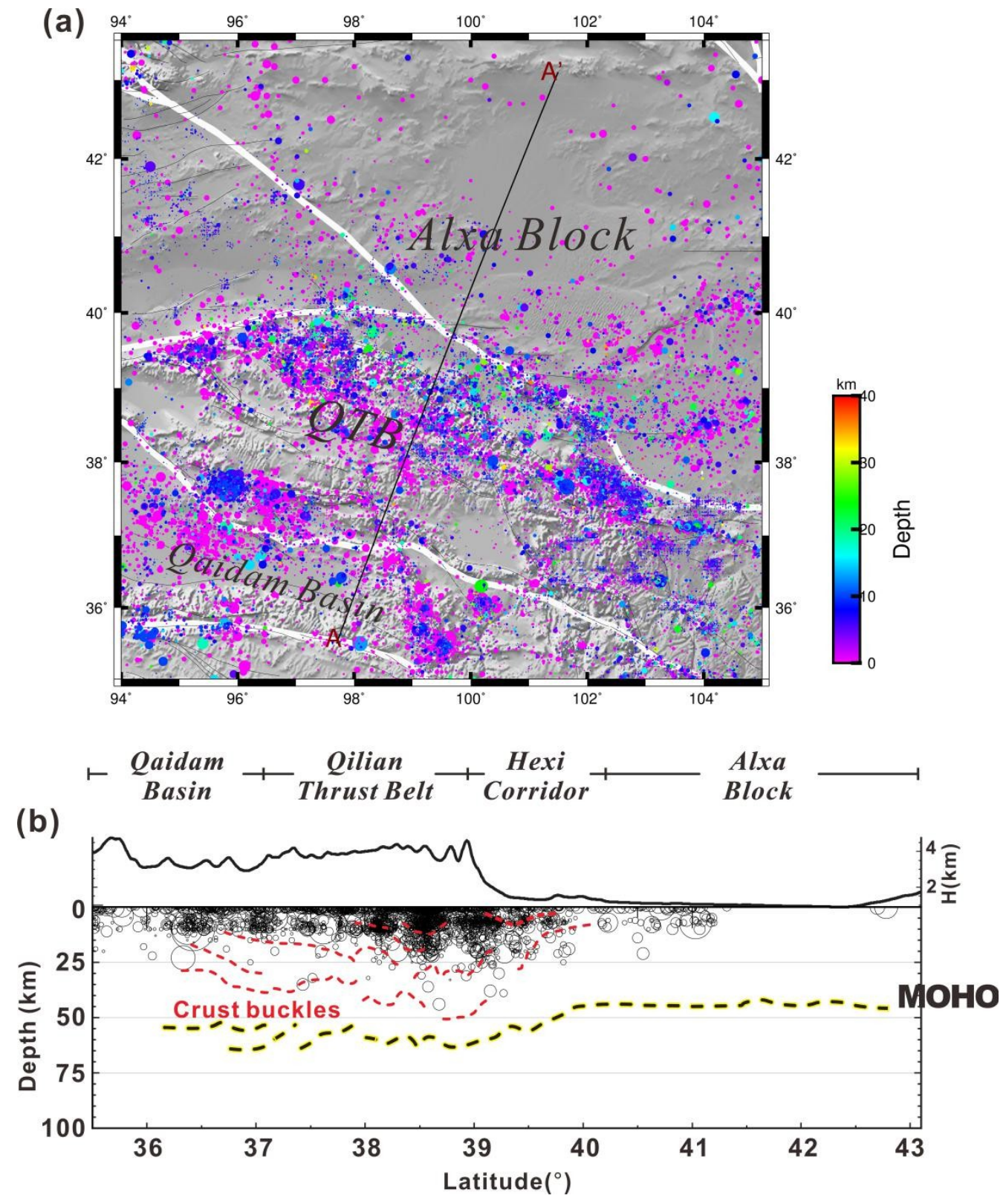

Figure 9. Map of Earthquakes in northeast Tibetan Plateau. (a) The distribution of earthquakes in northeast Tibetan Plateau, the depth of the event is marked by color (Feng et al., 2012, updated with new dataset in 2015). AA' is the profile of the seismic array as in Figure 2a. (b) Seismicity along the profile AA' and the crust buckles. Earthquakes since 1970 within a swath of $100 \mathrm{~km}$ wide along profile AA' with magnitude larger than ML3.0 are plotted. The Moho (black dashed line) and crust buckles (red dashed lines) are duplicated from Figure 5b. 


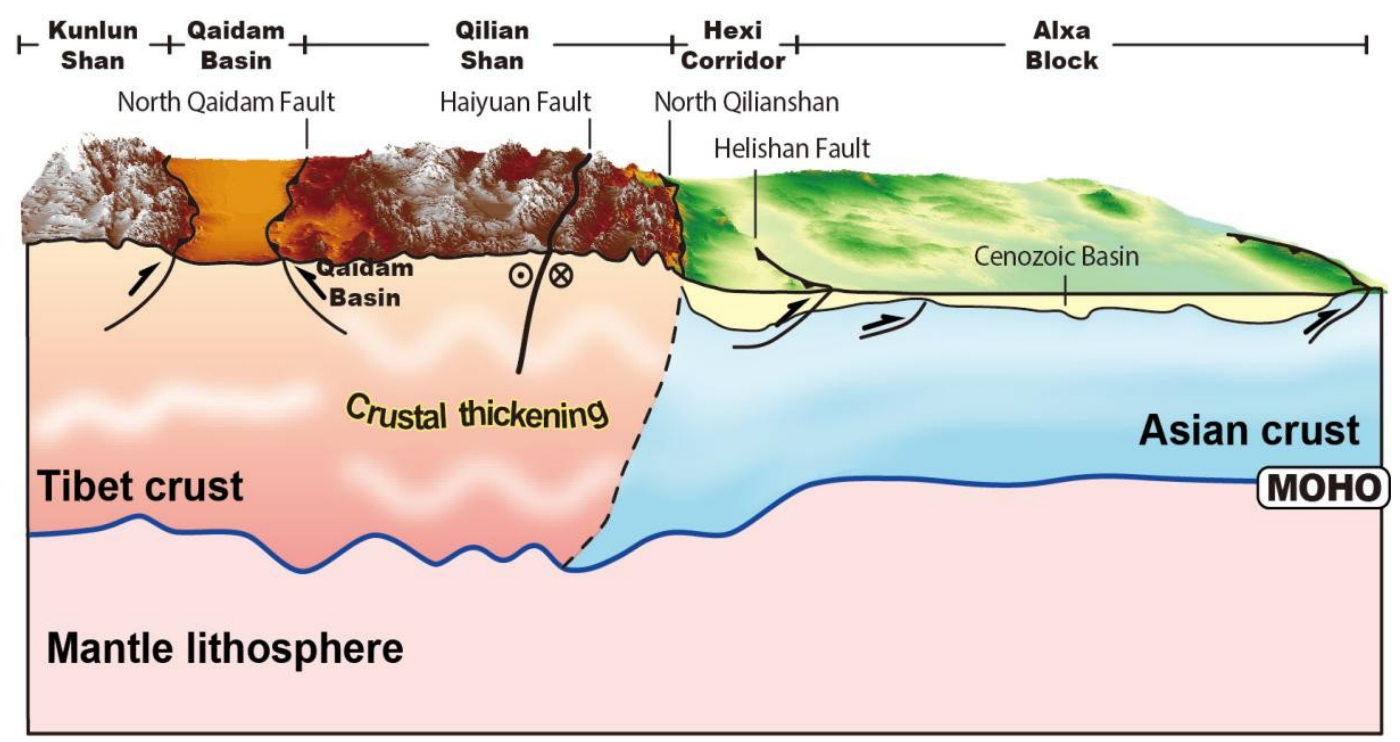

Figure 10. Conceptual model of the crustal structures across the north Tibetan Plateau, indicating pure-shear shortening of the northern front of the plateau between a rigid Alxa block and a relatively strong Qaidam Basin. 